\title{
THE AMERICAN JOURNAL OF PATHOLOGY
}

\begin{tabular}{lll}
\hline \hline VoLUMr XII & OctoBER, 1962 & NUMBER 4 \\
\hline \hline
\end{tabular}

\section{THE CELLULAR AND EXTRACELLULAR MORPHOLOGY OF THE GLOMERULAR STALK}

David B. Jones, M.D.; C. Babeer Muerler, M.D, and Max Menefe, M.D., Ph.D.

From the Departments of Pathology, Surgery, and Anatomy, State University of New York, Upstate Medical Center, Syracuse, N.Y.

Increased understanding of the structure of the renal glomerulus has followed its investigation with the electron microscope, and general agreement regarding the anatomic nature of the basement membrane, the endothelial cell and the epithelial cell has been reached. ${ }^{1-9}$ Such studies have not clearly defined the existence of a third cell type in the glomerular stalk, or refuted Elias' contention ${ }^{4}$ that this stalk is a mass of endothelial cells. Yamada, ${ }^{5}$ in 1955 , described a third cell as a distinct cell type. More recently Movat and Steiner ${ }^{\circ}$ have described such a cell, and Farquhar and Palade ${ }^{10}$ have presented preliminary evidence that third cells do exist and actually can be identified by their response to the presence of tiny particulate matter introduced into the blood. In order to elucidate its structure, this paper presents observations on the stalk area, the "mesangium" of Zimmerman, ${ }^{11}$ the cells which comprise the stalk, and the relationship of the basement membrane to the "fibromucin" of Jones ${ }^{12}$ or the "branching basement membrane material" of Farquhar, Vernier and Good ${ }^{3}$ and Churg, Grishman and Mautner. ${ }^{13}$ These observations have been made by utilizing the light microscope, silver-stained methacrylate sections, plastic and glass reconstructions and electron microscopy. From these observations we have concluded that the glomerulus contains 3 cell types - the third cell being the stalk cell. The characteristic feature of the stalk cell is its anatomic location and its relationship to the branching basement membrane material which we prefer to designate the sponge fibers of the stalk. The reader is re-

This work was supported by grants from the National Institutes of Health, United States Public Health Service, H-4300 and A-I393.

Accepted for publication, May 31, 1962. 
ferred to the several reviews and many publications which present other authors' concepts of this area. ${ }^{14}$

\section{Material and Methods}

The material used in this study came from normal human kidneys obtained at necropsy or during surgical procedures and from normal rat kidneys. The reconstructions presented herein were derived from tissue obtained at necropsy in a 5-year-old Negro boy dying from acute anaphylaxis to ragweed. Necropsy was performed within 2 hours of death. Other reconstructions in 5 patients aged 8 to 40 years have been made with similar findings; these are not pictured in this report. Electron microscopic observations were made upon rat kidneys perfused with osmic acid fixative ante mortem.

Human tissue obtained at necropsy was fixed in isotonic formalin neutralized with sodium acetate, dehydrated in alcohol, embedded in 8:1 butyl-methyl methacrylate and cut in a Porter-Blum microtome with glass knives at 0.25 to $0.13 \mu$. Sets of serial sections numbering between 50 and 100 each were cut and mounted on glass slides. After removal of the methacrylate by acetone, the sections were stained with a modified periodic acid-silver methenamine ${ }^{15}$ and counterstained with basic fuchsin (Fig. 7).

\section{Glass Reconstructions}

These were made from black and white photomicrographs of appropriate portions of the glomerular stalk seen in a series of sections cut at $0.25 \mu$ and stained as above. Photographic enlargement was made to such a scale that the lateral diameter corresponded to the enlargement gained by the thickness of the glass on which the reconstruction was to be painted. After appropriate enlargement, each micrograph was covered with a piece of glass, and the outline of the glomerular basement membrane, the sponge fibers of the stalk, and the cell nuclear margins were drawn on the glass with Clay Adams glass marking ink. White was chosen for coloring the glomerular basement membrane, blue for the sponge fibers of the stalk, black for the endothelial nuclei and red for the stalk cell nuclei. Cell margins were omitted because the magnifications with which we were dealing $(X 970)$ made it impossible to define accurately the plasma membranes of the endothelial cells or the stalk cells. Throughout this study, no observations were made upon the glomerular epithelial cells-the podocytes. The glass plates were cemented into groups of 6 , using Permount ${ }^{\circledR}$ in order to reduce light loss by refraction (Fig. 8).

\section{Plastic Reconstructions}

These were made from a series of $0.13 \mu$ sections magnified by photographic techniques to 17,000 diameters. The outlines of the basement membrane and the sponge fibers of the stalk were traced onto wax sheets of approximately $2.2 \mathrm{~mm}$. thickness. The outlines of the traced structures were then cut and removed from the sheets. The series of sheets was stacked in proper order, and a casting of basement membrane and sponge fibers was made with Ward's Bioplastic ${ }^{\circledR}$. There were no sponge fibers which failed to fill with Bioplastic by this method since a check of the original photographs showed that each fiber was always connected to a glomerular basement membrane at some point. A second series of wax plates was traced from the same photomicrographs except that the nuclei of the endothelial cells and third cells were traced and cut out. The nuclear outlines, not the sheets, were then stacked. These were fitted and trimmed so that they could be maneuvered into the approximate place from which they came. Molds were made of these nuclei, and they were then cast in Bioplastic (Fig. I).

\section{Electron Microscopy}

Electron microscopic observations of the stalk areas were made on rat kidneys perfused with osmic acid in vivo. Under light ether anesthesia, the abdomen of a 
fasting rat was opened, ties were placed around the upper abdominal aorta and left iliac artery. A needle was inserted into the right iliac artery, the vena cava was incised, and $2 \mathrm{ml}$. of buffered osmic acid fixative with polyvinylpyrrolidinone and amyl nitrite was injected into the iliac artery. The kidney was immediately removed, and small cortical fragments were dropped into the osmic fixative. After dehydration, the tissue was embedded in epoxy resin, cut with a glass knife in an L.K.B. microtome and examined in an RCA EMU-3D microscope.

\section{ObSERVATIONS}

For purposes of description, the glomerular basement membrane can be divided into two segments, one of which is the portion adjacent to the attenuated endothelium of the capillary (the capillary segment), and the other, the portion adjacent to the cell bodies which comprise the glomerular stalk (the stalk segment). In the stalk segment, the basement membrane is thicker than in the capillary segment, and when stained, it is more prominent because of its increased width and its serrated or wrinkled character. All of the observations which follow here relating to the glomerular basement membrane apply only to its stalk segment.

\section{The Sponge Fibers of the Stalk}

Arising on the stalk surface (as opposed to the epithelial surface) of the stalk segment of the glomerular basement membrane, projections from this membrane extended into the stalk cell area. These were multiple, interconnected and interlacing fibers which formed a spongy network (Figs. I to 6 and 8), found only in the stalk cell area. Within the interstices of this sponge lay the cytoplasm of the stalk cell. The nucleus of the stalk cell was generally ovoid in shape and fairly regular. It was neither indented nor traversed nor modified in shape in any major extent by the sponge fibers. The latter stained with silver or the periodic acidSchiff reaction in a fashion similar to the rest of the glomerular basement membrane, and by electron microscopy they merged into or arose from the basement membrane without noticeable change in character or electron density. Surrounding each sponge fiber was a sharply discernible plasma membrane which related to the basement membrane in other areas (Fig. 9). This suggests that the stalk cell cytoplasm surrounded and enveloped the sponge fibers, leaving the fibers extracytoplasmic at all places.

In our reconstructions, all of the sponge fibers were in continuity with the basement membrane at some point. The endothelial cell bodies did not lie within the interstices of the sponge fibers as did the stalk cells, but, rather, the endothelial cells lay adjacent to the sponge, either in a concavity in the sponge fibers or in a niche formed by sponge on one side and the capillary segment of the basement membrane on the other. The 
endothelial cell membrane occasionally lay adjacent to the plasma membrane of the stalk cell, though it was usually separated from it by a sponge fiber. The sponge fibers which separated the endothelial cell from the stalk cell formed an irregular lattice which served to complete the envelopment of the capillary by basement membrane material and sponge fiber material.

The stalk cell surface, however, was not a solid sheet of sponge fiber membrane (Figs. I and 5); its face was incomplete, and there was a fair portion of its area in which the stalk cell came into direct contact with the endothelial cell.

\section{The Stalk Cell}

In all previous descriptions of glomerular structure, authors have recognized and agreed upon the existence of epithelial and endothelial cells. There has been no uniformity of opinion as to whether or not there exists a third cell type in the glomerulus.

Our observations indicated that a third cell does exist, and we suggest that this cell be labeled the stalk cell. The stalk cells formed a continuous branching arbor to which the endothelial cells with their capillary lumens were attached. Surrounding the entire endothelial and stalk cell mass was the basement membrane of the glomerulus. It appeared that the stalk segment of the glomerular basement membrane was firmly held to the stalk cells by the sponge fibers which were intimately interlaced in this stalk. The stalk cells appeared to be individual cells and not a syncytium, and their apposition to each other was maintained by the interlacing sponge fibers with which the stalk cells formed a continuous firm pedicle or arbor upon which the capillaries were hung. The nucleus of the stalk cell had no particular characteristic except its position in the stalk. Nuclei of adjacent stalk cells could be moderately widely separated by a complex of sponge fibers within whose interstices could be found portions of stalk cell cytoplasm. The cytoplasm was intimately interlaced with sponge fibers which indented but did not penetrate the plasma membrane.

The stalk cells had a major surface opposed to the stalk segment of the glomerular basement membrane, but did not have a major surface opposed to the lumen of the capillary. The surface facing toward a capillary lumen was usually covered by a piece of sponge fiber or by an endothelial cell, either the cell body or a portion of its attenuated cytoplasm. In a few areas, under the influence of osmotic diuresis, the cytoplasm of an endothelial cell might develop an open space through which a small blunt projection from a stalk cell actually penetrated to a position wherein it was in contact with the capillary lumen. Under those circum- 
stances, these projections might become fairly long, and might terminate in a tiny cytoplasmic bulb which protruded into the capillary lumen (Fig. II).

We were unable to identify intracellular particles, organelles or other characteristics which were consistently different from the intracellular organization of endothelial cells and were unable to differentiate these two cells upon seeing only a portion of their cytoplasm in the electron microscope. The cytoplasmic density of the stalk cell could vary from less to greater than that of the endothelial cells (Figs. Io and I I), and the number of mitochondria, amount of ergastoplasm and the presence of fibrils were quite variable. The most characteristic feature of the stalk cell was its intimate and complex relation to the sponge fibers. A similar arrangement between sponge fiber and the endothelial cell did not exist. This arrangement of sponge fiber to stalk cell was best appreciated in the reconstructions and was more difficult to identify in high magnification electron micrographs. We now believe, however, that whenever we see a sponge fiber from the basement membrane projecting into a cell, that cell is a stalk cell and can be identified as such even though only a fragment of its cytoplasm is seen.

\section{The Endothelial Cell}

The body of the endothelial cell, with its nucleus, was generally found adjacent to the stalk cell, though not infrequently it might appear in any portion of the capillary circumference. The nucleus was generally round with minor indentations. The cytoplasm of the endothelial cell was not interlaced or invaginated by the sponge fibers of the stalk, though sponge fibers lay, on occasion, adjacent to its outer plasma membrane.

\section{Discussion}

The renal glomerulus has a complex arborized structure whose understanding demands the utmost of high resolution light and electron microscopy. The advent of epoxy resin embedding has made possible a new order of high resolution in electron microscopy while the modification of a periodic acid-silver methenamine stain counterstained with basic fuchsin has permitted the staining of sections cut at $0.25 \mu$ with enough intensity to provide a satisfactory resolution of stalk features with light microscopy.

We have found 3-dimensional reconstruction to be essential in understanding the organization of the stalk area. Movat and Steiner ${ }^{\circ}$ and Huhn, Steiner and Movat, ${ }^{16}$ seeing the same structure by light and electron microscopy, clearly surmised the 3-dimensional characteristics of the stalk. The discrepancies in previous observations of the stalk area 
can be understood by examining the techniques of electron microscopy. The interpretation of 3 -dimensional structure becomes hazardous with the examination of sections of 0.05 to $0.025 \mu$ thickness in a system in which the examination of serial sections is extremely difficult. Thus, 3-dimensional concepts have arisen by the use of electron microscopy as an adjunct to the more gross light microscope impressions in which serial sections are feasible. Hall ${ }^{17}$ studied sections cut at $2 \mu$ and stained with van Gieson's stain, and Elias ${ }^{4}$ used alum hematoxylin in his serial section study. These stains are pallid and nonspecific in sections of such thinness, and interpretations made from them are of questionable validity. The fine structure of the glomerulus is so complex that we have found sections as thin as $0.5 \mu$ to be too thick for proper interpretation of the finer components needed for 3-dimensional reconstruction and thus have used tissue cut at 0.25 or $0.13 \mu$. While the PAS method produces passable stains in glomeruli cut at $0.5 \mu$, only the periodic acidsilver methenamine stain, counterstained with basic fuchsin, was found to be satisfactory for 0.25 or $0.13 \mu$ sections.

Recently, Latta ${ }^{18}$ demonstrated a sparse distribution of collagen fibrils in the glomerulus of the normal rat, and Huhn, Steiner and Movat ${ }^{16}$ found features in stalk cells which they considered to be similar to structures found in smooth muscle. Benedetti and Marinozzi ${ }^{10}$ claimed to have demonstrated a greater number of cytoplasmic organelles in stalk cells than in endothelial cells. It appears to us that neither of these two observations is complete enough. Although some of the stalk cells have the characteristics of smooth muscle, these characteristic features are not always present. The range in number of cytoplasmic organelles in stalk cells of the rat is extensive, and the endothelial organelles may be either more or less numerous than these.

The role of the stalk cell, the endothelial cell, the sponge fibers and the stalk segment of the glomerular basement membrane in disease processes of the glomerulus has yet to be defined. Unpublished work by the authors indicates that there is proliferation, thickening and expansion of the sponge fibers in many glomerular disorders as major manifestations of glomerular scarring. This is associated, as well, with swelling, proliferation and degeneration of the stalk cells.

\section{SUMMARY}

A study of the stalk area of the renal glomerulus has been conducted utilizing 3-dimensional reconstructions of normal human kidney and electron micrographs of rat kidney. The serial sections used for the reconstructions were cut from methacrylate-embedded tissue. The electron micrographs were made utilizing osmic acid perfusion and epoxy resin embedding. 
A third cell type-the stalk cell-has been described in the renal glomerulus, and a complex arrangement of the basement membrane in the stalk area has been noted-the sponge fibers of the stalk. The stalk cell is in intimate relation with the sponge fibers which indent and invaginate the stalk but not the endothelial cell. The sponge fiber areas appear to exist as arborizations from the glomerular hilus, and we suggest that these fibers with their enmeshed stalk cells actually form the structure upon which the capillaries are hung as they wind their way into and out of the glomerular space. With such a concept, the stalk cells and sponge fibers actually do constitute a "mesangium," as Zimmerman originally proposed.

\section{REFERENCES}

I. Mueller, C. B.; Mason, A. D., JR, and Stout, D. G. Anatomy of the glomerulus. Am. J. Med., 1955, 18, 267-276.

2. Rhinehart, J. F.; Farquhar, M. G.; Jung, H. C., and Abul-Haj, S. K. The normal glomerulus and its basic reactions in disease. Am. J. Path., I953, 29, 2I-3I.

3. Farquhar, M. G.; Vernier, R. L., and Good, R. A. Studies on familial nephrosis. II. Glomerular changes observed with the electron microscope. Am. J. Path., 1957, 33, 791-81 7.

4. Elias, H. The Renal Glomerulus in Light and Electron Microscopy. In: Research in the Service of Medicine. G. D. Searle \& Co., Vol. 57.

5. Yamada, E. The fine structure of the renal glomerulus of the mouse. J. Biophys. \& Biochem. Cytol., 1955, 1, 551-566.

6. RHodin, J. Electron microscopy of the glomerular capillary wall. Exper. Cell Res., 1955, 8, 572-574.

7. Pak Poy, R. K. F. Electron microscopy of the mammalian renal glomerulus. The problems of intercapillary tissue and the capillary loop basement membrane. Am. J. Path., 1958, 34, 885-895.

8. McManus, J. F. A. Medical Diseases of the Kidney (an Atlas and Introduction). Lea \& Febiger, Philadelphia, I950, I 76 pp.

9. Movat, H. Z., and Steiner, J. W. Studies of nephrotoxic nephritis. I. The fine structure of the glomerulus of the dog. Am. J. Clin. Path., I96I, 36, 289-305.

io. Farquhar, M. G., and Palade, G. E. Functional evidence for the existence of a third cell type in the renal glomerulus. (Abstract) First Meeting of the American Society for Cell Biology, 1962.

I1. Zimmerman, K. W. Uber den Bau des Glomerulus der menschlichen Niere. Ztschr. mikr.anat. Forsch., 1929, 18, 520-522.

12. Jones, D. B. The Kidney. Inflammatory and Vascular Diseases of the Glomerulus. In: Analytical Pathology. Mellors, R. D.: (ed.). Blakiston Div., McGraw-Hill Book Co., New York, 1957, pp. 161-2 I 7.

13. Churg, J.; Grishman, E., and Mautner, W. Nephrotoxic serum nephritis in the rat. Electron and light microscopic studies. Am. J. Path., I960, 37, 729749.

14. Mueller, C. B. The structure of the renal glomerulus. Am. Heart J., 1958, 55, 304-322.

15. Jones, D. B. Nephrotic glomerulonephritis. Am. J. Path., 1957, 33, 313-329.

16. Huhn, D.; Steiner, J. W., and Movat, H. Z. Die Feinstruktur des Mesan- 
giums im Niereglomerulum von Hund und Mous. Ztschr. Zellforsch, 1962, 56, 213-230.

17. Hall, B. V. Studies of normal glomerular structure by electron microscopy. Proceedings of the Fifth Annual Conference on the Nephrotic Syndrome, Philadelphia, Nov. 5-7, 1953. National Nephrosis Foundation, Inc., New York, 1954, pp. I-39.

18. LATTA, H. Collagen in normal rat glomeruli. J. Ultrastruct. Res., 1961, 5, 364-373.

19. Benedetti, E. L., and Marnozzt, V. Sulla fine struttura del tessuto intercapillare nel glomerulo di Malpighi. Rass. fisiopat. clin., 1958, 30, Fasc. II, November, $1-36$. Jorsey.

We gratefully acknowledge the technical assistance of Mr. Allen Bell and Mrs. Lyanne

\section{LEGENDS FOR Figures}

Fic. I. A plastic reconstruction of a glomerulus from the kidney illustrated in Figures 7 and 8 , made from $0.13 \mu$ serial sections magnified 17,000 times. Note the holes in the sponge fiber lattice, through which the red stalk cell nucleus may be seen when viewed from the capillary lumen.

Fic. 2. A view of a plastic reconstruction with the upper half removed and without the stalk cell nucleus. The black structures are endothelial cell nuclei. Note the sponge network which encloses the stalk cell.

Fig. 3. A view of the upper half of a plastic reconstruction in which the sponge fibers have been painted with blue poster paint for emphasis. 

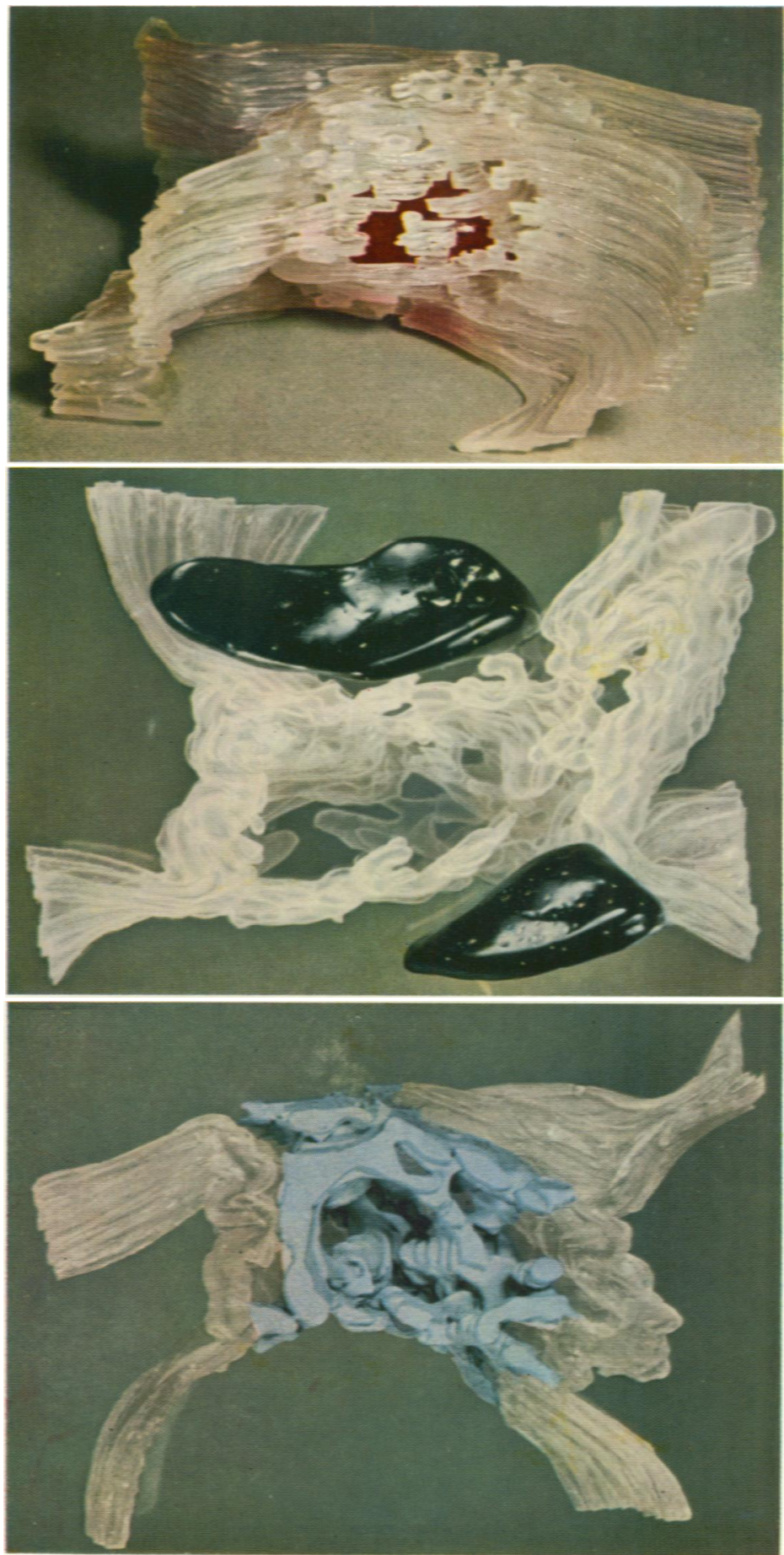
Fic. 4. A view of a plastic reconstruction with the red stalk cell nucleus in place. The black structures are endothelial nuclei.

Fic. 5. A glass plate reconstruction of the glomerular lobule shown in Figure 8 . White is basement membrane, blue is sponge fiber, black is endothelial cell nucleus, red is stalk cell nucleus, and epithelial cells have been omitted. Note the continuous sponge fiber lattice which forms a portion of the circumference of each capillary.

Fic. 6. The same glass plate reconstruction shown in Figure 5 at a deeper level. The same color key is used. Note that the red stalk cell nuclei are enclosed by the continuous sponge lattice. 

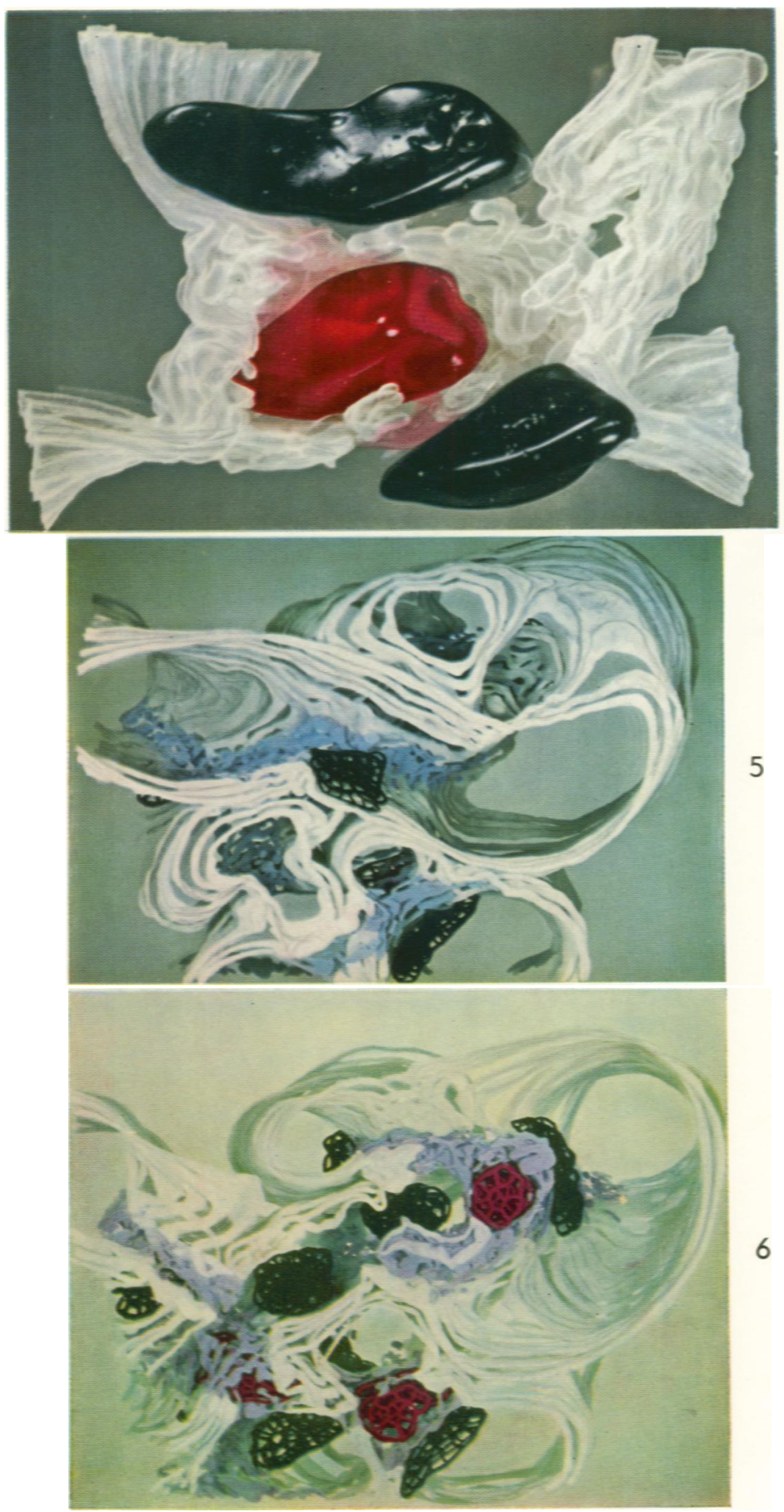
Fic. 7. The glomerular lobule in a 5-year-ald boy cut at $0.25 \mu$ and stained with periodic acid-silver methenamine and basic fuchsin. $X 1,700$.

Fic. 8. A glass plate reconstruction from serial sections of the same glomerular lobule. This gives a suggestion of the 3-dimensional appearance of the stalk. 

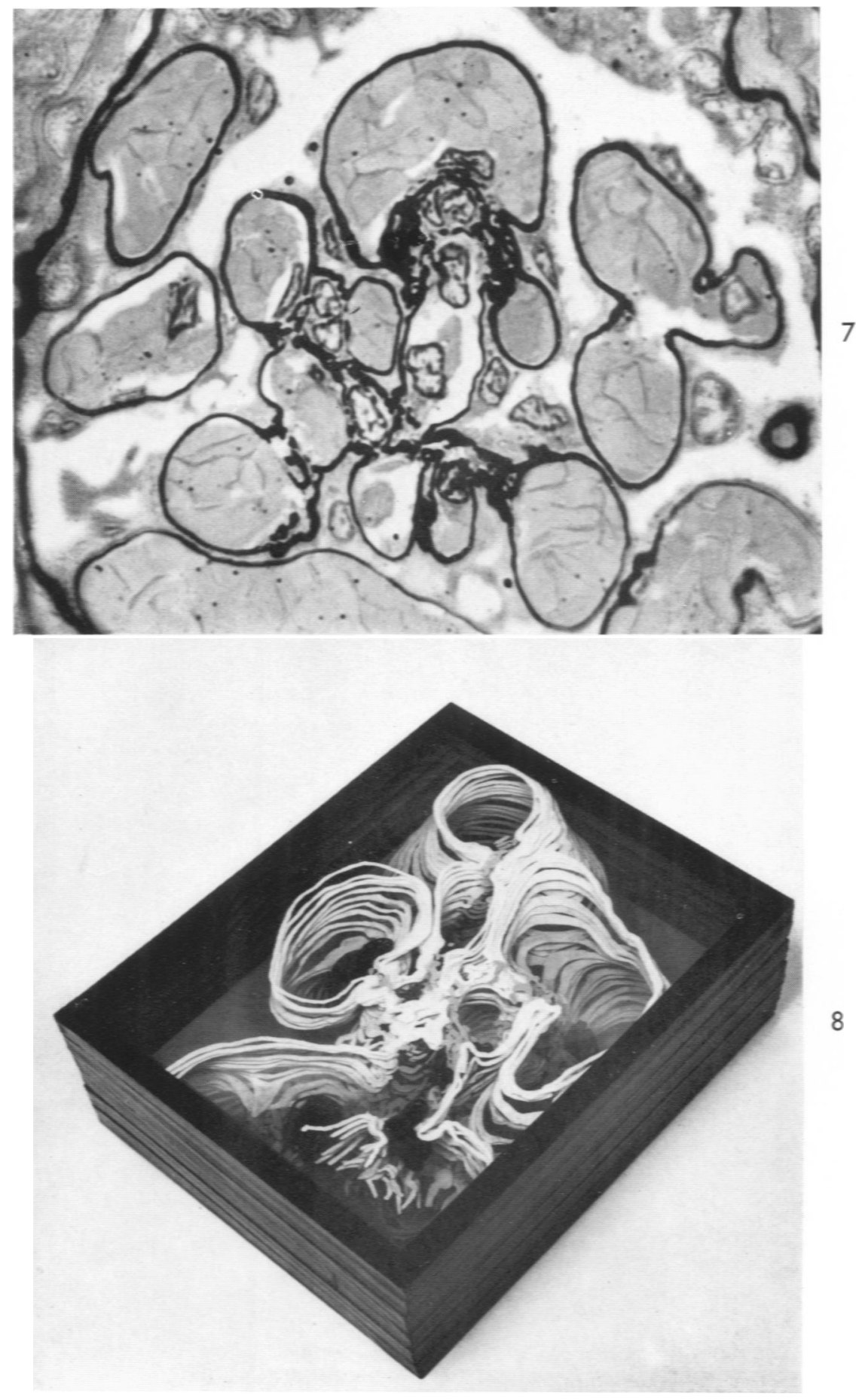


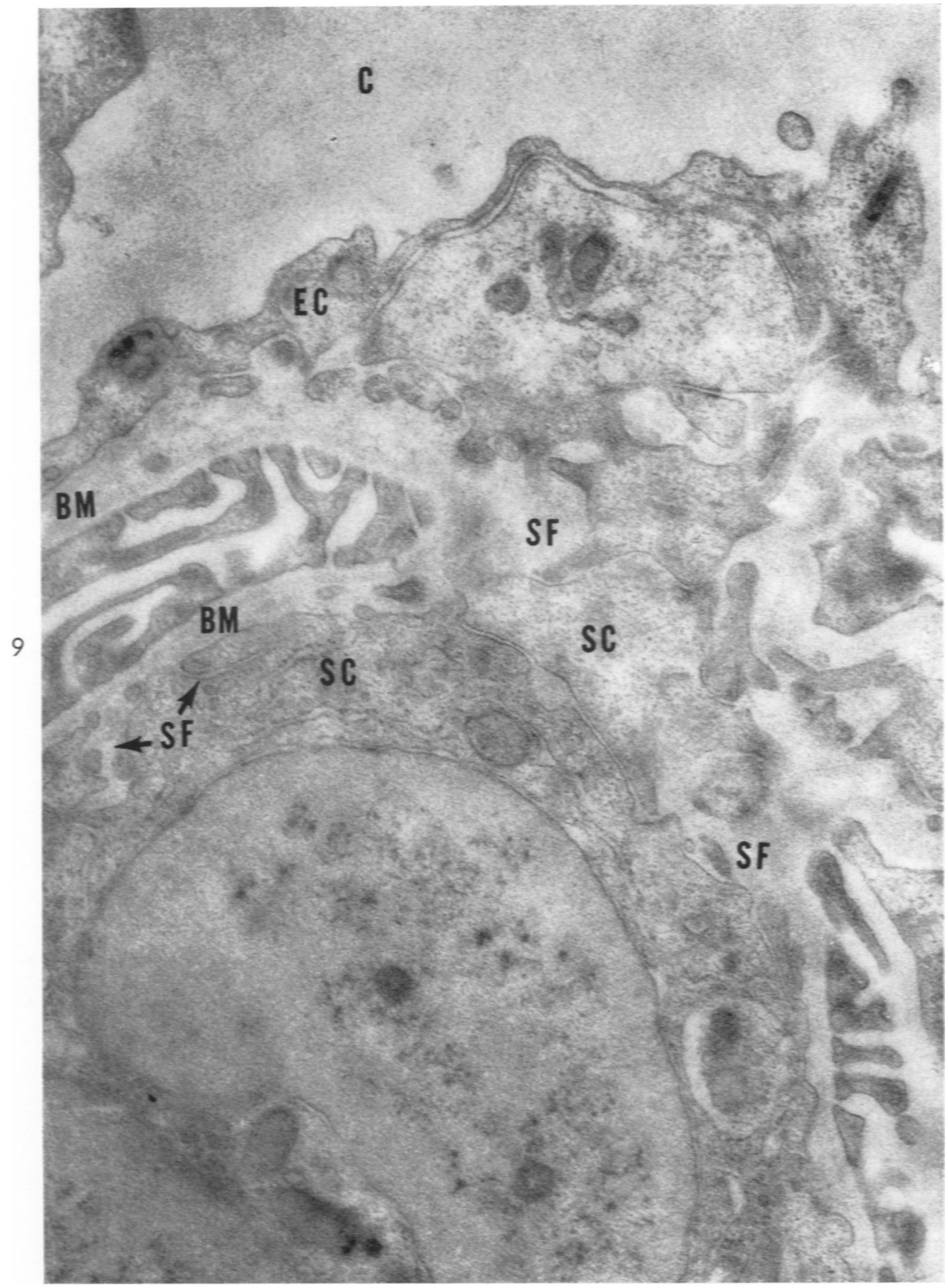

FIG. 9. An electron micrograph of the stalk area of a rat glomerulus. BM. basement membrane: SF. example of sponge fibers of the stalk: SC. stalk cell cytoplasm; EC, endothelial cell cytoplasm: C. capillary lumen. Note the variability in the number of organelles in various stalk cells and the intimate relationship of the sponge fibers to the stalk cell components. $\times 35.700$. 


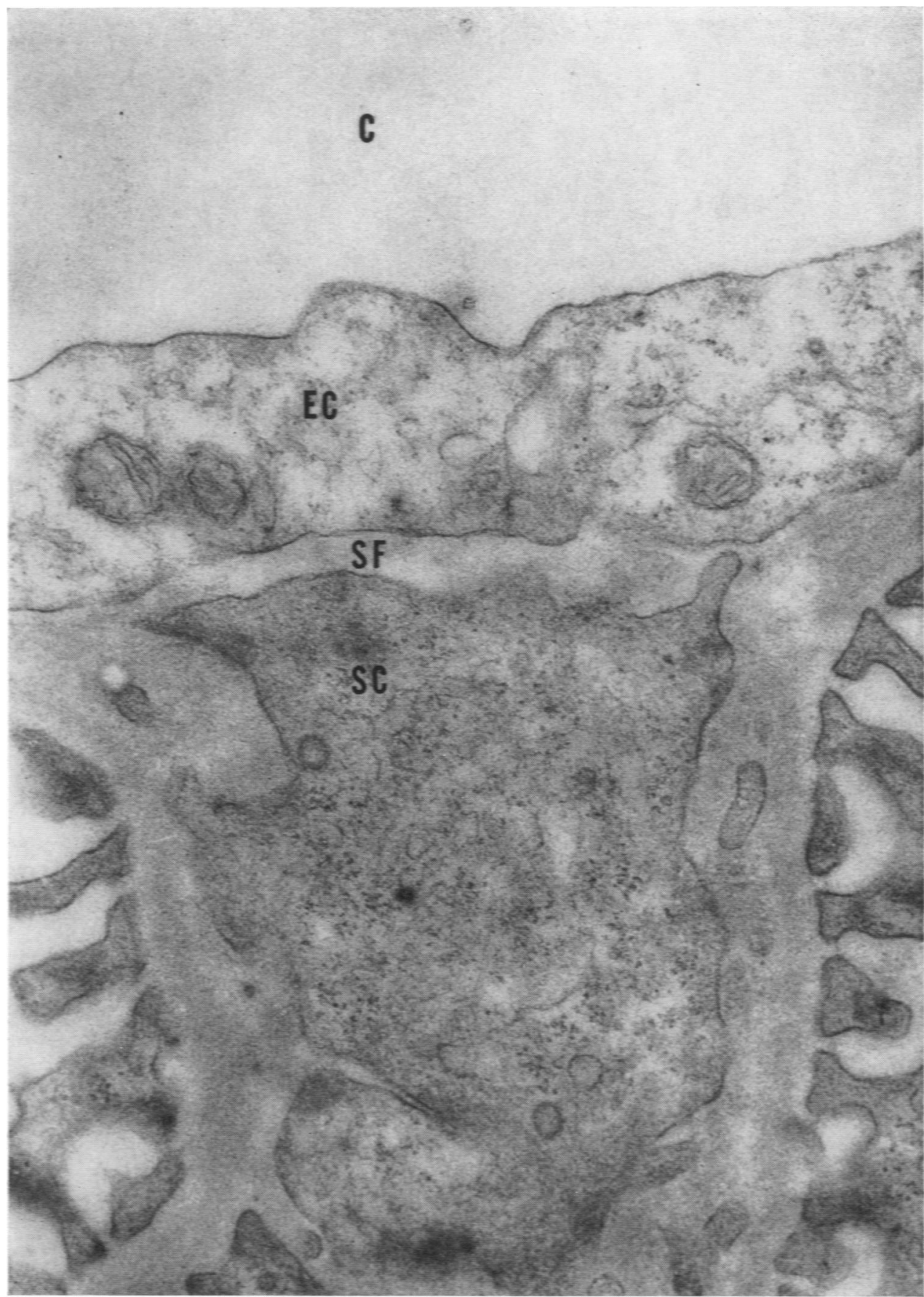

Fig. Io. An electron micrograph of a portion of an endothelial cell (EC) adjacent to a stalk cell (SC) with a sponge fiber (SF) between the two cells. Note the difference in the cytoplasmic density between the two cells. $\times 35.700$. 


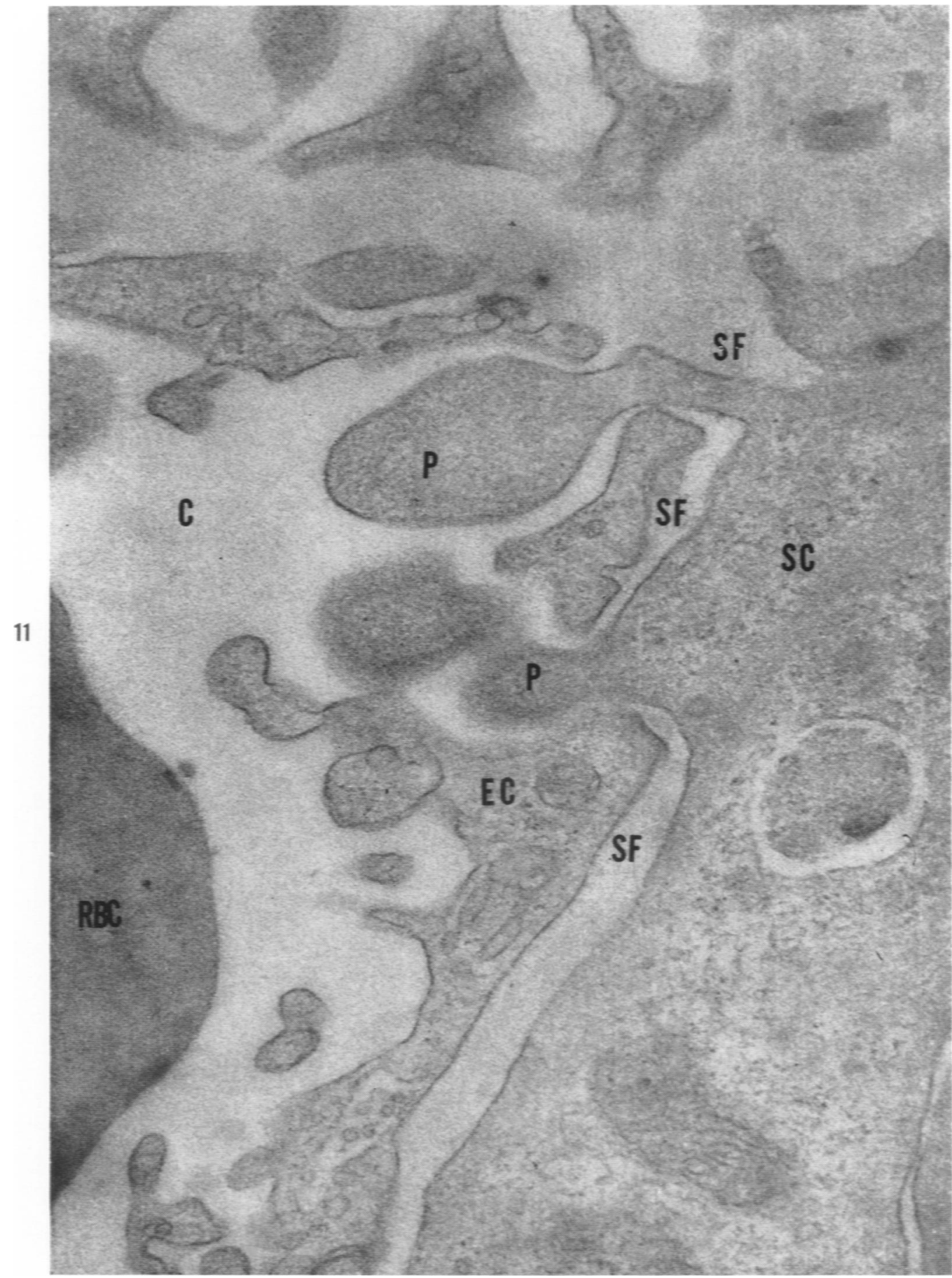

Fic. I I. An electron micrograph showing a capillary lumen (C) which contains a red blood cell $(\mathrm{RBC})$ and two projections (P) from a stalk cell (SC). The projections enter the capillary lumen through apertures in the sponge fiber ( $\mathrm{SF}$ ) of the stalk and the endothelial cell (EC). From the kidney of a rat subjected to osmotic diuresis (work still in progress). $\times 40,800$. 